This item was submitted to Loughborough's Research Repository by the author.

Items in Figshare are protected by copyright, with all rights reserved, unless otherwise indicated.

\title{
Addressing the challenges of fabricating microwave antennas using conductive threads
}

PLEASE CITE THE PUBLISHED VERSION

http://dx.doi.org/10.1109/EuCAP.2012.6205910

PUBLISHER

(C) IEEE

VERSION

AM (Accepted Manuscript)

LICENCE

CC BY-NC-ND 4.0

\section{REPOSITORY RECORD}

Chauraya, Alford, Shiyu Zhang, W.G. Whittow, Tessa Acti, R.D. Seager, Tilak Dias, and J.C. Vardaxoglou. 2019. "Addressing the Challenges of Fabricating Microwave Antennas Using Conductive Threads". figshare. https://hdl.handle.net/2134/10720. 
This item was submitted to Loughborough's Institutional Repository (https://dspace.lboro.ac.uk/) by the author and is made available under the following Creative Commons Licence conditions.

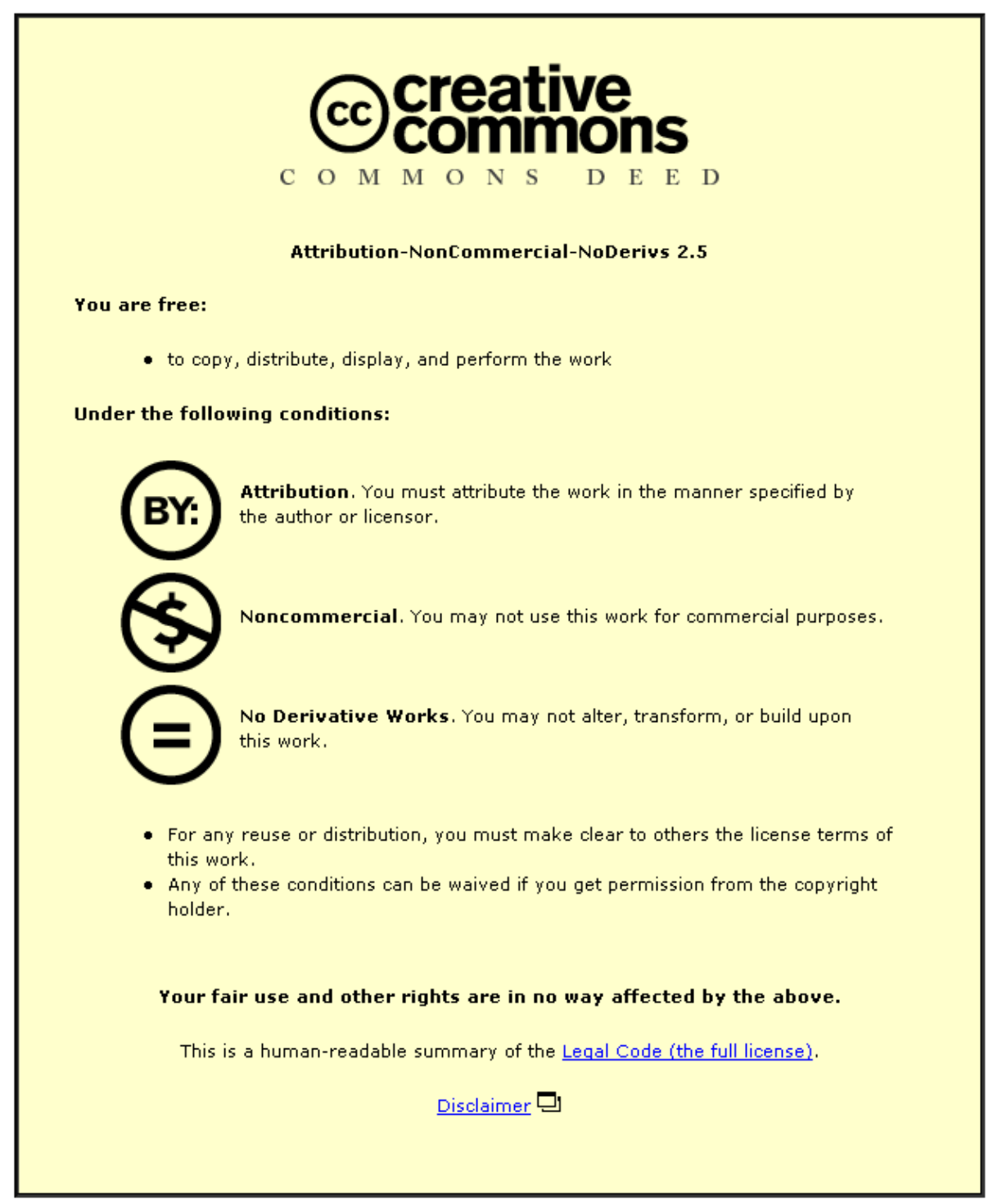

For the full text of this licence, please go to: http://creativecommons.org/licenses/by-nc-nd/2.5/ 


\title{
Addressing the Challenges of Fabricating Microwave Antennas Using Conductive Threads
}

\author{
Alford Chauraya $^{\# 1}$, Shiyu Zhang ${ }^{\# 2}$, William Whittow ${ }^{* 3}$, Tessa Acti ${ }^{\wedge 4}$, Rob Seager ${ }^{\# 5}$, Tilak Dias ${ }^{\wedge}$, Yiannis C. \\ Vardaxoglou $^{\# 7}$ \\ "School of Electronic, Electrical and Systems Engineering, Loughborough University, Loughborough, UK \\ "Antrum Ltd, Loughborough Innovation Centre, Loughborough University Science \& Enterprise Park, Ashby Rd, LE11 3AQ, UK \\ ^Centre for Research in Advanced Textiles (CReATe), School of Art and Design, Nottingham Trent University, \\ Nottingham, NG1 4BU, UK \\ 11a.chauraya@lboro.ac.uk; ${ }^{2}$ s.zhang@lboro.ac.uk; ${ }^{3}$ will.whittow@antrum.co.uk; ${ }^{4}$ tessa.acti02@ntu.ac.uk \\ ${ }^{5}$ r.d.seager@lboro.ac.uk; ${ }^{6}$ tilak.dias@ntu.ac.uk; 7j.c.vardaxoglou@lboro.ac.uk
}

\begin{abstract}
This paper examines the advantages and challenges of creating microwave patch antennas using conducting threads. The antennas are produced using automated embroidery machinery that could be easily scaled up to mass manufacture. Textile patch antennas are designed that resonate between 2 and 2.7GHz depending on the substrate. Different stitch directions and compositions were considered. Measured gain and efficiency results are included in this paper.
\end{abstract}

Keywords: conductive thread; wearable antenna; embroidery

\section{INTRODUCTION}

Antennas are fundamentally important to the modern wireless age in which we live. One of the next big areas of antenna development is wearable antennas. Applications include emergency services, the military, athlete monitoring, medical monitoring/telemedicine, fashion, leisure, camping, pet and child monitoring and clothing security.

Wearable antennas have been widely studied in recent years [1-7]. Advantages include flexibility and comfort to the user. The ability to integrate them into clothing means antennas can not be left behind, dropped or lost and do not need to be held in the hand. The challenges of wearable antennas are obtaining high levels of physical and electromagnetic performance and to minimize the effect of bending, crumpling or the presence of the user.

Wearable antennas are typically made from flexible conductors; this paper will examine the potential of using conducting threads. Computerized embroidery machines can be used to fabricate the textile antennas quickly and on a mass manufacturing scale with the flexibility to change the designs at minimal costs or inconvenience. Using automated machinery requires that suitable threads must be chosen that do not break when under substantial tension [8].
Embroidering the antenna directly into the clothing will mean the design becomes an aesthetic point of interest rather than an unattractive add-on. Using embroidered conductive threads will also negate the need for glue and hence improve the durability in harsh environments and allow washability. It will also reduce the number of fabrication processes which reduces manufacturing costs. However, conductive threads can be lossy compared to bulk metals. Typically the effective conductivity of these threads can vary between 1 x $10^{4}$ and $5 \mathrm{x}$ $10^{4} \mathrm{~S} / \mathrm{m}$ [9].

Other authors who have considered designing antennas using conductive threads include [3, 10-14]. Due to the difficulties associated with the materials and the embroidery process, these antennas often have disappointing efficiencies. Previous papers in this area generally do not quote the efficiency or gain values.

Previously we have shown that the conduction is better along the thread direction rather than in-between threads [8]. This highlights the complexity of designing antennas using conductive threads and the authors have found that the stitch direction, stitch type, spacing between the stitches as well as the settings of the embroidery machinery all need to be considered to improve the electromagnetic performance.

\section{ANTENNA DESIGN}

The patch antennas in this paper were made using metal clad polymer threads with the Barudan embroidery machinery at Nottingham Trent University, please see [8] for more details. The computerised embroidery process allows a great degree of control including different stitch densities and stitch directions. The antennas were embroidered onto cotton fabric and placed on an FR4 substrate with the aid of non-conducting glue and pieces of plastic tape as shown in Figure. 1. A rigid FR4 substrate with a copper ground was used in this work to allow a fair comparison with the conventional rigid patch antennas.

This work was funded by the IEMRC. 


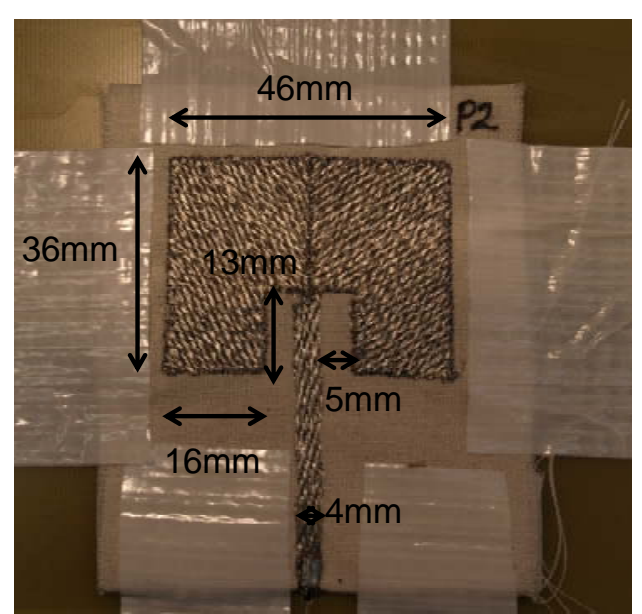

Figure 1. Patch antenna with diagonal stitching.

\section{RESULTS}

The patch in Figure 1 was simulated using EMPIRE $\mathrm{XCcel}^{\mathrm{TM}}$ finite-difference time-domain (FDTD) software. The $10 \mathrm{~dB}$ bandwidth level, efficiency and gain of the patch antenna on FR4 (tan delta $=0.015)$ were $31 \mathrm{MHz}, 40 \%$ and 3.31dBi.

The measured return loss results are shown in Figure 2. Six patch antennas were considered 1) a conventional patch on FR4; 2) a copper patch placed on a layer of cotton which was in turn placed on top of the FR4 substrate; 3) Fabric Patch 1 was a copper impregnated nylon sheet placed on cotton above the FR4 substrate; 4 \& 5) Fabric Patches 2 and 3 were made from conducting threads but using different stitch directions and 6) Patch 4 consisted of conductive threads embroidered onto an alternative base material other than cotton. This allowed the conducting thread antennas with different stitch directions to be compared to the equivalent version made from copper. It was observed that the layer of cotton on top of the FR4 substrate reduced the effective permittivity and decreased the electrical size.

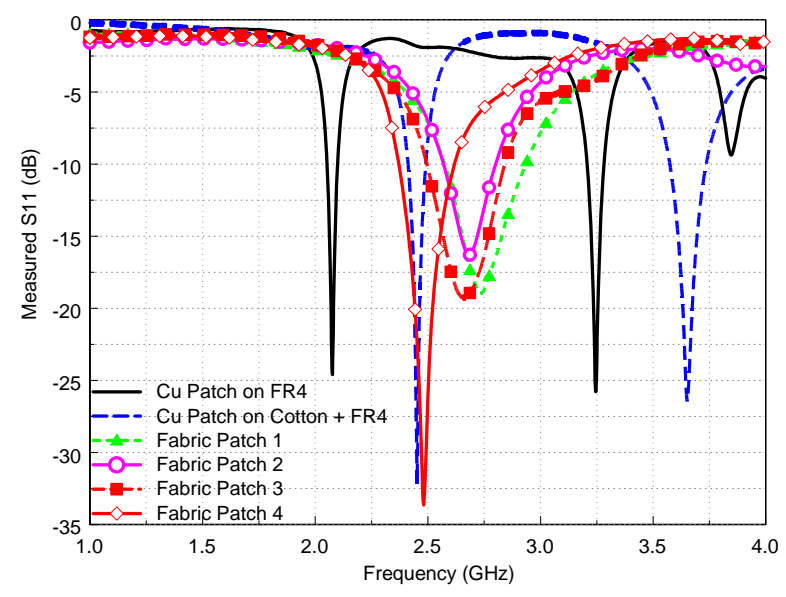

Figure 2. Measured return loss results.

The gain and efficiency results were measured in an anechoic chamber and are shown in Table 1.

The measured results show that the copper antenna agreed well with the simulations and that the reduced efficiency is largely due to the lossy substrate. The conducting nylon sheet (Fabric Patch 1) had an efficiency of 36.1\% compared to $46.3 \%$ for the copper patch on cotton. The conducting threads produced a wider bandwidth but a reduced efficiency which indicates the embroidered patch antenna is lossy. Patch 4 had an improved efficiency compared to the other embroidered antennas which was due to the antenna being embroidered onto a different base textile which was less lossy than cotton.

Table 1. Measured patch antenna results.

\begin{tabular}{|c|c|c|c|c|}
\hline $\begin{array}{c}\text { Antenna } \\
\text { Description }\end{array}$ & $\begin{array}{c}\text { Frequency } \\
\text { (GHz) }\end{array}$ & $\begin{array}{c}\mathbf{1 0 ~ d B} \\
\text { Bandwidth } \\
\text { (MHz) }\end{array}$ & $\begin{array}{c}\text { Peak } \\
\text { Gain } \\
\text { (dBi) }\end{array}$ & $\begin{array}{c}\text { Antenna } \\
\text { Efficiency } \\
\text { (\%) }\end{array}$ \\
\hline $\begin{array}{c}\text { Cu Patch on } \\
\text { FR4 }\end{array}$ & 2.076 & 46 & 3.8 & 38.6 \\
\hline $\begin{array}{c}\text { Cu Patch on } \\
\text { Cotton and } \\
\text { FR4 }\end{array}$ & 2.451 & 79 & 5.1 & 46.3 \\
\hline $\begin{array}{c}\text { Fabric } \\
\text { Patch 1 }\end{array}$ & 2.658 & 240 & 5.1 & 36.1 \\
\hline $\begin{array}{c}\text { Fabric } \\
\text { Patch 2 }\end{array}$ & 2.684 & 220 & -6.8 & 5.3 \\
\hline $\begin{array}{c}\text { Fabric } \\
\text { Patch 3 }\end{array}$ & 2.658 & 350 & -3.4 & 7.6 \\
\hline $\begin{array}{c}\text { Fabric } \\
\text { Patch 4 }\end{array}$ & 2.495 & 67 & 1.4 & 22.6 \\
\hline
\end{tabular}

\section{DISCUSSION AND CONCLUSIONS}

The efficiency of the embroidered antennas is related to the losses in the substrate and the losses in the base fabric that supports the embroidery. The losses due to the conductive thread will be dependent on the thickness, material and continuity of the metallic cladding, the frequency and the electrical connection between adjacent threads. It is expected that the losses from antennas made from conductive textiles will be greater than conventional rigid antennas and there will be a trade off in the electromagnetic performance and the flexibility, comfort to the user, cost and the speed of fabrication.

The challenges involved in designing antennas with conductive threads include: sourcing the correct materials (in terms of conductivity, strength and flexibility); assessing the behavior of many threads forming a continuous object and improving the efficiency. Note that the conducting threads themselves used in this paper had comparable performance to copper for simple transmission lines [8] and this demonstrates the difficulty of creating 2-D patch antennas from conductive threads as opposed to 1-D transmission lines. There is potential to further improve the efficiency by optimising the stitch 

Antennas \& Propagation, 2012.

geometry and also the parameters (eg tension and speed) of the embroidery machinery. This paper has only considered a partially flexible antenna and has used a conventional rigid substrate and ground plane, however, the authors have the capability to embroider fully flexible antennas.

\section{REFERENCES}

[1] T. Kellomäki, W. G. Whittow, J. Heikkinen, and L. Kettunen, "2.45 GHz plaster antennas for health monitoring," presented at EuCAP 2009, Berlin, Germany, 2009.

[2] L. Ma, R. Edwards, and W. G. Whittow, "A notched hand wearable ultra wideband W printed monopole antenna for sporting activities," presented at 2008 Loughborough Antennas \& Propagation Conference, Loughborough, UK, 2008.

[3] J. C. G. Matthews, B. P. Pirollo, A. J. Tyler, and G. Pettitt, "Wideband Body Wearable Antennas," presented at Wideband, Multiband Antennas and Arrays for Defence or Civil Applications, 2008 Institution of Engineering and Technology Seminar on, 2008. D. Gaspar and A. Moreira, "Belt antenna for wearable applications," presented at Antennas and Propagation Society Int. Symp, Charleston, SC, USA, 2009.

[5] B. Sanz-Izquierdo, J. C. Batchelor, and M. I. Sobhy, "Button antenna on textiles for wireless local area network on body applications," Microwaves, Antennas \& Propagation, IET, vol. 4, pp. 1980-1987, 2010.

[6] W. G. Scanlon and N. E. Evans, "Numerical analysis of bodyworn UHF antenna systems," Electronics \& Communication Engineering Journal, vol. 13, pp. 53-64, 2001.
[7] B. Gupta, S. Sankaralingam, and S. Dhar, "Development of wearable and implantable antennas in the last decade: A review," presented at Microwave Symposium (MMS), 2010 Mediterranean, 2010.

[8] T. Acti, S. Zhang, A. Chauraya, W. G. Whittow, R. Seager, T. Dias, and Y. Vardaxoglou, "High Performance Flexible Fabric Electronics for Megahertz Frequency Communications," presented at 2011 Loughborough Antennas \& Propagation Conference (LAPC), Loughborough, UK, 2011.

Y. Ouyang and W. Chappell, "Measurement of Electrotextiles for High Frequency Applications," presented at IEEE MTT-S International Microwave Symposium Digest, 2005.

[10] R. Jung-Sim, C. Yong-Seung, L. Jae-Hee, T. Youndo, N. Sangwook, and K. Tae Jin, "Embroidered Wearable Multiresonant Folded Dipole Antenna for FM Reception," Antennas and Wireless Propagation Letters, IEEE, vol. 9, pp. 803-806.

[11] D. Cottet, J. Grzyb, T. Kirstein, and G. Troster, "Electrical characterization of textile transmission lines," Advanced Packaging, IEEE Transactions on, vol. 26, pp. 182-190, 2003.

[12] T. Maleszka and P. Kabacik, "Bandwidth properties of embroidered loop antenna for wearable applications," presented at Wireless Technology Conference (EuWIT), 2010 European.

[13] Y. Ouyang and W. J. Chappell, "High Frequency Properties of Electro-Textiles for Wearable Antenna Applications," Antennas and Propagation, IEEE Transactions on, vol. 56, pp. 381-389, 2008.

[14] R. D. Seager, A. Chauraya, J. C. Vardaxoglou, and P. de Maagt, "Towards a compact low frequency woven antenna," presented at Antennas and Propagation Society International Symposium, 2009. APS/URSI '09. 2009. 